\title{
Reflection does not undermine self-interested prosociality
}

\author{
David G. Rand ${ }^{1,2,3}$ * and Gordon T. Kraft-Todd ${ }^{1}$ \\ ${ }^{1}$ Department of Psychology, Yale University, New Haven, CT, USA \\ ${ }^{2}$ Department of Economics, Yale University, New Haven, CT, USA \\ ${ }^{3}$ Organizational Behavior, School of Management, Yale University, New Haven, CT, USA
}

\section{Edited by:}

Antonio M. Espín, Universidad de

Granada, Spain

Reviewed by:

Molly Crockett, University College London, UK

Paul Kayhan Piff, University of

California, Irvine, USA

David DeSteno, Northeastern

University, USA

${ }^{*}$ Correspondence:

David G. Rand, Department of

Psychology, Economics and

Management, Yale University,

2 Hillhouse Ave., New Haven,

CT 06511, USA

e-mail: david.rand@yale.edu
The cognitive basis of prosocial behavior has received considerable recent attention. Previous work using economic games has found that in social dilemmas, intuitive decisions are more prosocial on average. The Social Heuristics Hypothesis (SHH) explains this result by contending that strategies which are successful in daily life become automatized as intuitions. Deliberation then causes participants to adjust to the self-interested strategy in the specific setting at hand. Here we provide further evidence for the $\mathrm{SHH}$ by confirming several predictions regarding when and for whom time pressure/delay will and will not alter contributions in a Public Goods Game (PGG). First, we replicate and extend previous results showing that (as predicted by the $\mathrm{SHH}$ ) trust of daily-life interaction partners and previous experience with economic games moderate the effect of time pressure/delay in social dilemmas. We then confirm a novel prediction of the $\mathrm{SHH}$ : that deliberation should not undermine the decision to benefit others when doing so is also individually payoff-maximizing. Our results lend further support to the $\mathrm{SHH}$, and shed light on the role that deliberation plays in social dilemmas.

Keywords: cooperation, economic games, prosociality, moral psychology, dual process

\section{INTRODUCTION}

Cooperation is a key component of life, from the cells in our bodies up through our personal and professional interactions and the relationships between nations, and thus is a major focus of study across the natural and social sciences (Hardin, 1968; Ostrom, 1990; Batson and Moran, 1999; Milinski et al., 2002; Boyd et al., 2003; Fehr and Fischbacher, 2003; Bartlett and Desteno, 2006; Levin, 2006; Herrmann et al., 2008; Crockett, 2009; Cushman and Macindoe, 2009; Goetz et al., 2010; Sigmund, 2010; Zaki and Mitchell, 2011; Apicella et al., 2012; Espín et al., 2012; Piff et al., 2012; Rand and Nowak, 2013; Hauser et al., 2014; Peysakhovich et al., 2014). The individual costs of cooperation, however, pose a problem: why are people willing to help others? Here we consider this question using the dual-process model of decisionmaking, which posits that decisions can be thought of as resulting from competition between two general systems (Sloman, 1996; Stanovich and West, 1998; Chaiken and Trope, 1999; Miller and Cohen, 2001; Kahneman, 2003; Frederick, 2005): one that is fast, automatic, and intuitive; and another that is slow, controlled, and deliberative.

Using this dual-process perspective to consider prosociality, the following questions arise (Zaki and Mitchell, 2013): are we intuitively selfish and only cooperate through active self-control? Or is our automatic predisposition to be cooperative, with deliberation favoring selfishness? To shed light on this issue, recent studies have examined the effect of experimentally manipulating the level of intuition vs. deliberation on prosociality in economic games. Doing so using time pressure/delay (Rand et al., 2012, 2014a,b), cognitive load (Cornelissen et al., 2011; Schulz et al., 2014), or application of transcranial direct current stimulation to the right lateral prefrontal cortex (Ruff et al., 2013) has suggested that deliberation favors selfishness. Other studies have found no significant effect of cognitive load (Hauge et al., 2009) or time pressure (Tinghög et al., 2013; Verkoeijen and Bouwmeester, 2014), but no studies to our knowledge find a significant positive effect of deliberation on prosociality in economic games. (Some studies have used decision time correlations to try to gain insight into the role of intuition vs. deliberation and find opposing results Rubinstein, 2007; Piovesan and Wengström, 2009; Rand et al., 2012; Nielsen et al., 2014; recent work, however, explains these inconsistencies by demonstrating that fast response times are not a good proxy for intuitive decision-making, and that actual cognitive process manipulations are required instead of just correlational analyses Evans et al., 2014).

To explain this overall negative effect of deliberation on cooperation, we have proposed the "Social Heuristics Hypothesis" (SHH) (Rand et al., 2014b). The SHH adds a dual process perspective to previous theories related to cultural differences and norm internalization (Bowles and Gintis, 2002, 2003; Henrich et al., 2005, 2010; Chudek and Henrich, 2011). Specifically, the SHH posits that people adopt strategies that are successful in daily life as default (automatically applied) heuristics for social interaction. In new or atypical social situations, one's first response is to apply these heuristics. Deliberation then tailors responses to the details of the present situation. Based on this logic, the SHH makes specific predictions about when deliberation should and should not undermine one-shot anonymous cooperation. In this paper, we test three such predictions by examining cooperation in a one-shot Public Goods Game (PGG) where decisions are made under time pressure 
(i.e., made more intuitive) or time delay (i.e., made more deliberative).

First, in a standard one-shot anonymous social dilemma, intuition should favor the behavior which is typically payoffmaximizing in one's lives daily life, while deliberation should always favor selfishness (because selfishness is payoff maximizing in one-shot anonymous social dilemmas). The presence in daily life of repeated interactions, reputation, and the threat of sanctions typically makes cooperation payoff-maximizing outside the lab: if others will only cooperate with you when you have behaved cooperatively in the past, self-interest dictates that you cooperate; and as a result, most people choose to cooperate under these circumstances (Axelrod, 1984; Milinski et al., 2002; Dal Bó, 2005; Nowak and Sigmund, 2005; Rand et al., 2009; Dal Bó and Fréchette, 2011; Fudenberg et al., 2012; Rand and Nowak, 2013). We argue that this is the case for most subjects in lab experiments, who live in Western communities with strong institutions and norms of cooperation. Therefore, we expect that most subjects will have high levels of inter-personal trust, and as a result peoples' intuitions will favor cooperation on average.

But this should not be true for everyone: even in contexts where reciprocity is possible, if most of the people you interact with are defectors, then you maximize your payoff by also defecting (leading to the formation of non-cooperative intuitions). Therefore, promoting deliberation should only undermine cooperation among people whose daily life interaction partners are cooperative (and thus have developed cooperative intuitions). People who live in a world where most others are non-cooperative have defection as their default, and thus should be unaffected by cognitive process manipulations in the context of one-shot economic games.

Preliminary support for this prediction comes from the correlational results of Rand et al. (2012)'s Study 10, where faster decisions were more cooperative among people with high interpersonal trust, but decision time did not predict cooperation among those with low interpersonal trust. (Furthermore, the median level of trust in Rand et al. (2012)'s Study 10 was 7 on a 10 point scale, and nearly twice as many subjects were above the scale mid-point as compared to below, supporting our suggestion that most subjects are trusting). This prediction is also supported by work showing that exposure to laboratory environments where cooperation was either advantageous (long repeated Prisoner's Dilemma games) or disadvantageous (short repeated Prisoner's Dilemmas) influenced subsequent behavior in oneshot anonymous games among subjects who relied on heuristics, but not among those who were deliberative (Peysakhovich and Rand, 2013). Here we seek to test this prediction using an actual experimental manipulation of cognitive process, rather than just decision-time correlations or individual differences in cognitive style.

Second, at the heart of the $\mathrm{SHH}$ is overgeneralization: intuitive responses from daily life get misapplied in the one-shot anonymous interactions of the laboratory. Thus, we would not expect intuitions to favor cooperation among subjects that have substantial previous experience with one-shot economic game experiments, as they will have had an opportunity to recalibrate their automatic responses (or to learn to be on guard against them). Prior support for this prediction comes from Rand et al. (2012)'s Study 9, in which a writing exercise that induced an intuitive mindset resulted in more cooperation than one inducing a deliberative mindset, but only among subjects that were inexperienced with economic game experiments (i.e., "naïve"). Additional support comes from Rand et al. (2014b), where (i) cooperation under time pressure in experiments run on MTurk systematically decreased over a 2 year period, during which time the MTurk subject pool became much more experienced with behavioral experiments, and (ii) this pattern was reproduced in a single experiment where cooperation was higher under time pressure than time delay among naïve subjects, but did not differ based on time constraint among experienced subjects.

There remains some question regarding the role of naivety, however, as Verkoeijen and Bouwmeester (2014) found no effect of time pressure/delay in a sample of subjects all reporting to be naïve (note, however, that in this study naivety was assessed at the outset of the experiment, and it was made clear that only naïve subjects would be allowed to participate; thus there is reason to believe that many subjects may have under-reported their level of experience). Here, we thus seek to again replicate the moderating effect of naivety, and to test for the joint moderation of naivety and interpersonal trust (i.e., intuition is only predicted to favor cooperation among subjects who are both naïve and trusting).

Third, deliberation should not reduce prosociality in settings where no conflict exists between the individual and group (such as the games used in Saijo and Nakamura, 1995; Brandts et al., 2004; Kummerli et al., 2010). If, because of a modified payoffstructure, the collectively optimal action is also the individually optimal action, deliberative decisions should be just as prosocial as intuitive decisions. Therefore, we predict that the presence of a social dilemma should moderate the effect of deliberation on cooperation. This is not a trivial prediction: if deliberation was reducing contributions in previous experiments for a reason other than the pursuit of self-interest, for example a desire to avoid extreme responses, then it should continue to do so even with this altered payoff structure. Here we present the first test of this prediction.

\section{EXPERIMENTAL DESIGN}

To assess these three predictions, we recruited 963 American participants (38\% female, mean age 30.9 years) using the online labor market Amazon Mechanical Turk (MTurk; Paolacci et al., 2010; Buhrmester et al., 2011; Horton et al., 2011; Amir et al., 2012; Rand, 2012) to play a single one-shot PGG in groups of four. In keeping with standard wages on MTurk, each participant received a $\$ 0.50$ show-up fee, and then chose how much of a 40 cent endowment to keep vs. contribute to a "common project" (using a radio button with options of $0,10,20,30$, and 40 cents, and having no default selected). All contributions were multiplied by a factor $x$ and split evenly among the four group members. Subjects made their decisions asynchronously, and payoffs were determined using ex post matching. No deception was used, and this research was approved by the Yale University Human Subjects Committee.

To manipulate the relative role of intuition vs. deliberation, a time constraint was imposed on the decision screen. In the 
"Time Pressure" condition, participants were asked to decide as quickly as possible and given at most $10 \mathrm{~s}$ (a timer counted down from 10). In the "Time Delay" condition, participants were asked to carefully consider their decision and told to wait at least $10 \mathrm{~s}$ before deciding (a timer counted up from 0). Participants were only notified about the time constraint upon arriving at the screen where they had to make their contribution decision, to prevent them from deliberating ahead of time to a greater extent in the time pressure condition (Rand et al., 2013). A total of $7.2 \%$ of participants did not obey the time constraint. We include these subjects in our analysis to avoid selection problems that impair causal inference, as highlighted by Tinghög et al. (2013).

To evaluate our first two predictions, we set $x=2$, creating a social dilemma: the aggregate payoff of all group members (i.e., social welfare) is maximized by contributing everything, but each individual receives only 1 cent back for every 2 cents contributed and thus loses money on contributing. In a postexperimental questionnaire, we followed Rand et al. (2012) and assessed the cooperativeness of participants' daily life interaction partners by asking "To what extent do you feel you can trust other people that you interact with in your daily life?" using a 7 point scale from "Very little" to "Very much" (mean 4.69, median 5; 16.8\% below mid-point; $61.3 \%$ above mid-point). We also assessed whether participants had previous experience with economic games by asking "To what extent have you participated in other studies involving the dividing up of money on MTurk before taking this HIT?" using a 5 point scale from "Never" to "Very often." We follow Rand et al. (2012, 2014b) and categorize participants as Naïve if they answered "Never" (15\% of participants were Naïve). Combining predictions 1 and 2 we predict a positive three-way interaction between time pressure, trust, and naivety, such that increasing intuitiveness increases cooperation only among subjects who are both trusting and naïve.

We test our third prediction by setting $x=6$. Here, the social dilemma disappears: for each unit a player contributes, she receives 1.5 units back from the pool, so all players contributing everything is both socially optimal and individually optimal. Thus, if deliberation undermines cooperation in social dilemmas because of a focus on self-interest, we should find no effect of manipulating deliberation in this "No Dilemma" condition. This leads us to predict no effect of time pressure in the No Dilemma condition, and a positive four-way interaction between time pressure, trust, naivety, and being in the Social Dilemma condition.

After making their decision, participants were asked which contribution amount maximized the group's payoff (\$0.40 in both Dilemma and No Dilemma conditions), and which amount maximized their individual payoff ( $\$ 0.00$ in Dilemma, $\$ 0.40$ in No Dilemma). Comprehension is assessed after the decision rather than beforehand to avoid inducing a deliberative mindset, as per (Rand et al., 2012). A total of $31.6 \%$ of subjects answered one or both questions incorrectly (this rate of non-comprehension is well in line with previous studies using economic games on Mechanical Turk, Horton et al., 2011; Rand et al., 2012, 2014b; Engel and Rand, 2014). As our central manipulation was the alteration of the payoff structure to remove the social dilemma in the No Dilemma condition, we exclude subjects who failed the comprehension questions in our main analyses. Comparing the Social Dilemma and No Dilemma conditions, the fraction of subjects incorrectly answering the question about the socially optimal choice did not vary significantly [Pearson chi2 $\left.{ }_{(1)}=0.10, p=0.76\right]$, but significantly more subjects in the No Dilemma condition gave the incorrect answer for the individually optimal choice [20.0\% in Social Dilemma, $41.1 \%$ in No Dilemma, Pearson chi2 $(1)=52.9, p<0.001]$. To address potential selection bias concerns when comparing the Social Dilemma and No Dilemma conditions, we replicate our cross-condition analyses including non-comprehenders and show that the results are qualitatively equivalent.

Our analyses were performed using linear regression with robust standard errors, taking contribution amount as the dependent variable.

\section{RESULTS}

We begin by examining the Social Dilemma condition (Figure 1, $x=2$ ) and evaluating our first two predictions regarding the joint moderation of time pressure by naivety and trust. We find the predicted positive three-way interaction between time pressure, naivety and trust when predicting contribution (Table 1 $\mathrm{Col} 2, p=0.013$; including demographic controls: Table $1 \mathrm{Col} \mathrm{3}$, $p=0.012$ ): among naïve subjects that are high in trust, time pressure increases contribution. Moreover, when restricting to

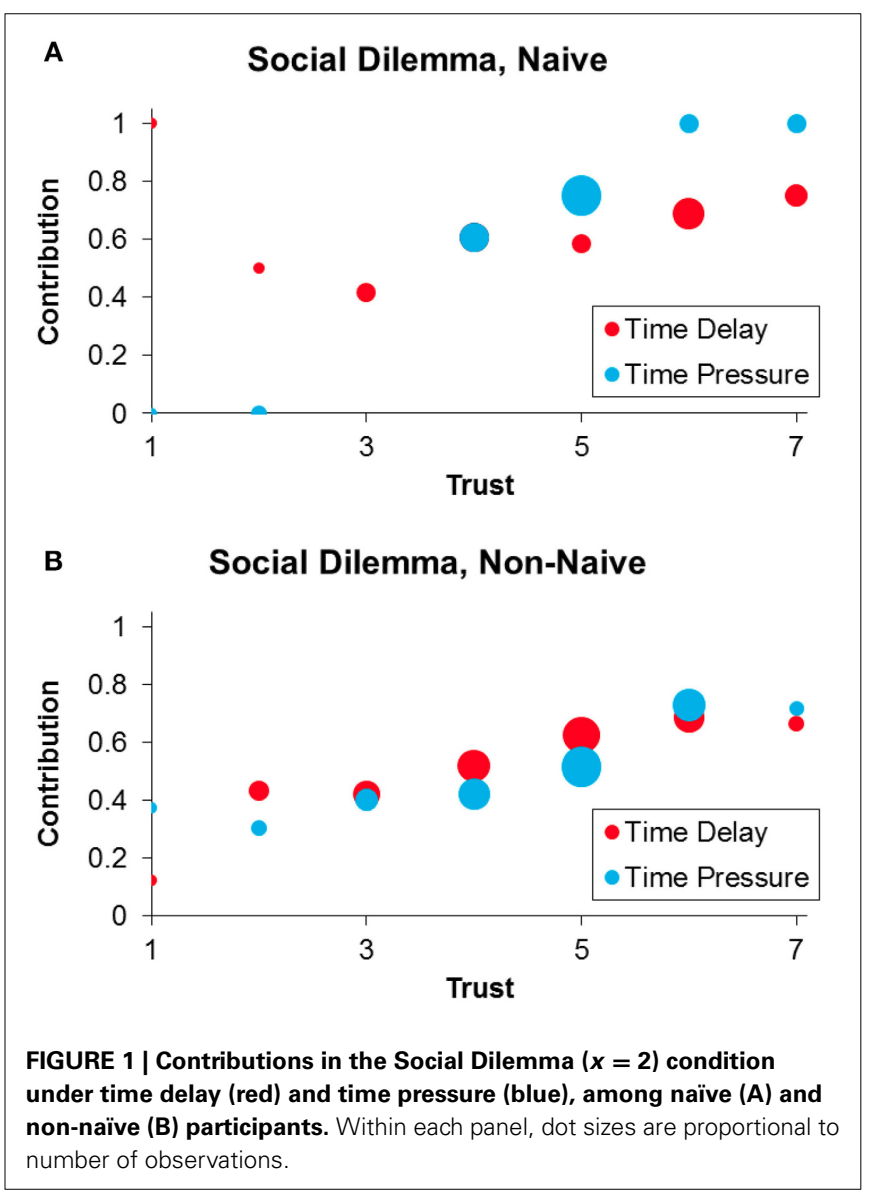


Table 1 | Linear regressions with robust standard errors predicting PGG contribution in the Social Dilemma condition.

Social dilemma $(x=2)$

\begin{tabular}{|c|c|c|c|}
\hline & \multicolumn{3}{|c|}{ Social dilemma $(x=2)$} \\
\hline & (1) & (2) & (3) \\
\hline Time pressure (TP) & $-1.453(1.655)$ & $-4.666(5.970)$ & $-4.594(6.027)$ \\
\hline Naïve & $4.018(2.217)$ & $11.46(10.33)$ & $12.16(10.65)$ \\
\hline Trust & $3.401 * *(0.570)$ & $3.059 * *(0.891)$ & $2.982 * *(0.886)$ \\
\hline TP $\times$ Naïve & & $-24.17(12.44)$ & $-24.86 *(12.59)$ \\
\hline TP $\times$ Trust & & 0.570 (1.257) & $0.554(1.260)$ \\
\hline Naïve $\times$ Trust & & $-1.988(2.022)$ & $-2.020(2.088)$ \\
\hline TP $\times$ Naïve $\times$ Trust & & $5.994 *(2.390)$ & $6.131 *(2.435)$ \\
\hline Age & & & $0.172 *(0.0804)$ \\
\hline Female & & & $-0.960(1.731)$ \\
\hline Education dummies & No & No & Yes \\
\hline Constant & $7.063 *(2.790)$ & $8.897 *(4.097)$ & $27.68 * *(3.300)$ \\
\hline Observations & 395 & 395 & 395 \\
\hline R-squared & 0.088 & 0.102 & 0.125 \\
\hline
\end{tabular}

Subjects failing the comprehension questions are excluded.

Robust standard errors in parentheses.

${ }^{* *} p<0.01,{ }^{*} p<0.05$.

subjects that are both naïve and have above median trust (the group the $\mathrm{SHH}$ predicts should have cooperative intuitions), time pressure significantly increases contribution relative to time delay (coeff $=11.7, p=0.023$ ). Thus, we confirm our first two predictions.

Next we evaluate our third prediction by examining the effect of time pressure on contribution in the No Dilemma condition (Figure 2). As predicted, we find no significant main effect of time pressure (Table $2 \mathrm{Col} 1, p=0.93$ ), and no significant interactions involving time pressure (Table $2 \mathrm{Col} 3$ and 4 , all $p>0.40$ ).

To support the meaningfulness of this null result, we conduct a power calculation based on the meta-analysis of Rand et al. (2014b) where the average effect of time pressure in PGGs was found to be an increase in contribution of $7.22 \%$ of the endowment. Our sample size of 292 comprehending subjects in the No Dilemma condition is large enough to detect an effect of that size with power of 0.84 . Therefore, it is unlikely that we failed to find a significant effect due to lack of power.

Furthermore, our central prediction was not this null result, but instead a predicted positive four-way interaction between time pressure, naivety, trust and a Social Dilemma dummy when combining data from both conditions. Indeed, we find this four-

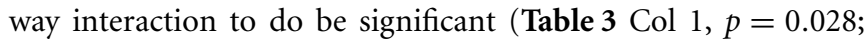
including demographic controls: Table $3 \mathrm{Col} 2, p=0.028)$. Furthermore, when restricting to subjects that are both naïve and have a higher-than-median level of trust, we find a significant positive interaction between time pressure and the Social Dilemma condition $(p=0.005)$. Thus, we confirm our third prediction.

We now address potential concerns related to selection effects arising from the fact that more subjects failed the comprehension question regarding individually optimal behavior (and thus were excluded) in the No Dilemma condition. To do so, we include all subjects regardless of whether they failed the comprehension

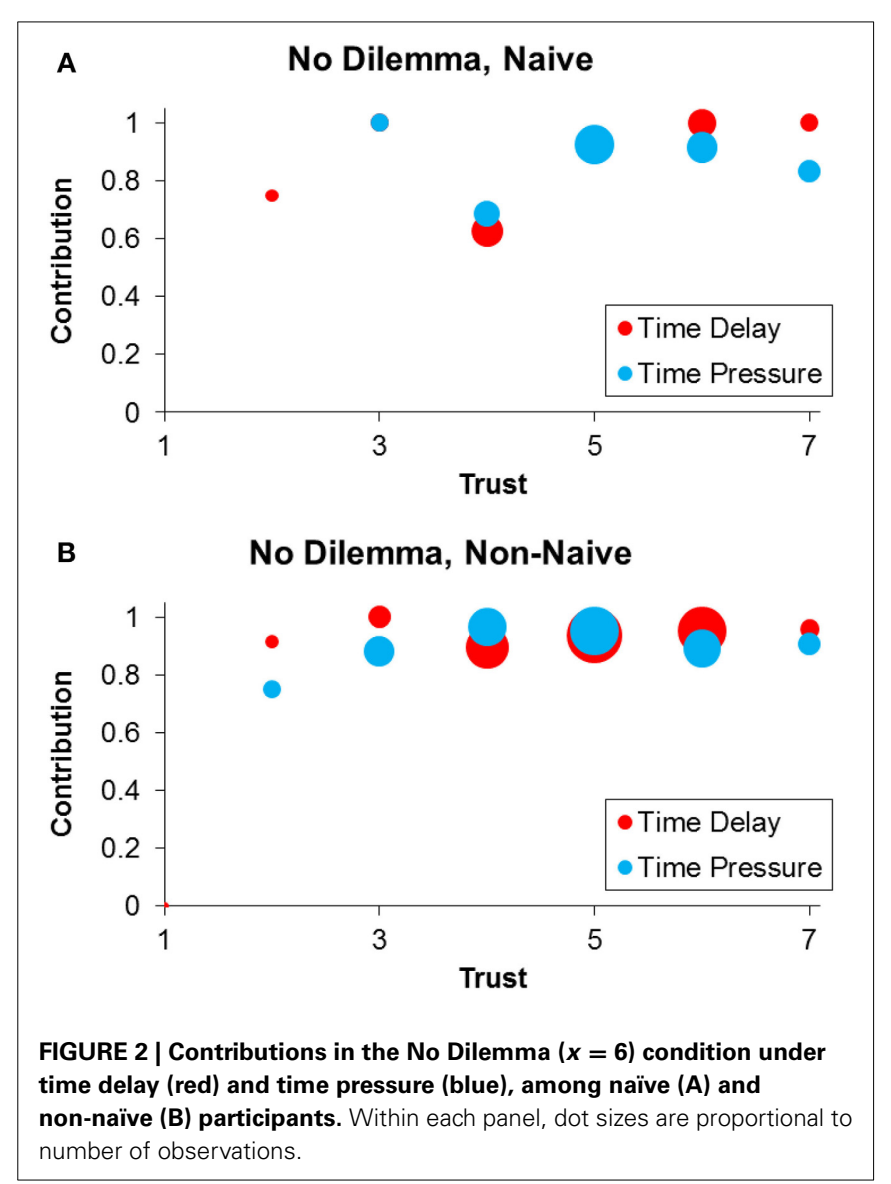

Table 2 | Linear regressions with robust standard errors predicting PGG contribution in the No Dilemma condition.

\section{No dilemma $(x=6)$}

\begin{tabular}{lcrr}
\hline & $\mathbf{( 1 )}$ & $\mathbf{( 2 )}$ & $\mathbf{( 3 )}$ \\
\hline Time pressure (TP) & $-0.0847(0.998)$ & $3.632(6.163)$ & $2.898(6.308)$ \\
Naïve & $-2.305(1.598)$ & $-10.23(10.13)$ & $-12.83(10.50)$ \\
Trust & $0.925(0.533)$ & $1.186(0.905)$ & $0.771(0.982)$ \\
TP $\times$ Naïve & & $8.817(14.51)$ & $9.877(14.59)$ \\
TP $\times$ Trust & & $-0.791(1.205)$ & $-0.601(1.227)$ \\
Naïve $\times$ Trust & & $1.598(1.670)$ & $2.228(1.753)$ \\
TP $\times$ Naïve $\times$ Trust & & $-1.680(2.543)$ & $-1.958(2.570)$ \\
Age & & No & $0.0865 * *(0.0316)$ \\
Female & & 292 & $1.055(0.879)$ \\
Education dummies & No & 0.036 & Yes \\
Constant & $32.62 *(2.879)$ & $31.37 *(4.769)$ & $34.32 * *(3.751)$ \\
Observations & 292 & 0.065 \\
R-squared & 0.027 & & 292 \\
\hline
\end{tabular}

Subjects failing the comprehension questions are excluded.

Robust standard errors in parentheses.

${ }^{* *} p<0.01$.

questions, and add a control for failing comprehension. We also include an interaction between the Social Dilemma dummy and the failed comprehension dummy, because in the Social Dilemma condition, comprehension failure (i.e., not understanding it is a 
Table 3 | Linear regressions with robust standard errors predicting PGG contribution across both conditions.

\begin{tabular}{|c|c|c|c|c|}
\hline & (1) & (2) & (3) & (4) \\
\hline Time pressure (TP) & $3.632(6.150)$ & $4.126(6.237)$ & $-4.467(5.457)$ & $-4.827(5.457)$ \\
\hline Naïve & $-10.23(10.11)$ & $-12.99(10.42)$ & $-24.27 * *(8.647)$ & $-25.29 * *(8.541)$ \\
\hline Social dilemma (SD) & $-22.47 * *(6.284)$ & $-22.89 * *(6.403)$ & $-26.33 * *(5.761)$ & $-26.57 * *(5.798)$ \\
\hline TP $\times$ Naïve & $8.817(14.48)$ & $9.129(14.69)$ & $22.35 *(10.81)$ & $21.53 *(10.97)$ \\
\hline Naïve $\times$ SD & $21.69(14.46)$ & $24.38(14.72)$ & $37.44 * *(13.21)$ & $38.76 * *(13.31)$ \\
\hline Naïve $\times$ Trust & $1.598(1.666)$ & $2.305(1.732)$ & $4.289 * *(1.532)$ & $4.577 * *(1.516)$ \\
\hline Trust $\times$ SD & $1.873(1.269)$ & $2.029(1.295)$ & $2.846 *(1.169)$ & $2.907 *(1.176)$ \\
\hline TP $\times$ Naïve $\times$ SD & $-32.99(19.10)$ & $-33.24(19.26)$ & $-37.04 *(17.18)$ & $-36.40 *(17.43)$ \\
\hline TP $\times$ Naïve $\times$ Trust & $-1.680(2.537)$ & $-1.781(2.577)$ & $-3.915^{*}(1.985)$ & $-3.748(2.019)$ \\
\hline Failed Comprehension $\times \mathrm{SD}$ & & & $11.50 * *(2.133)$ & $11.19 * *(2.160)$ \\
\hline Age & & $0.139 * *(0.0467)$ & & $0.0871 *(0.0433)$ \\
\hline Female & & $-0.112(1.071)$ & & $0.0900(0.917)$ \\
\hline Education dummies & No & Yes & No & Yes \\
\hline Constant & $31.37 * *(4.759)$ & $41.94 * *(8.509)$ & $35.61 * *(4.305)$ & $37.83^{* *}(7.792)$ \\
\hline Observations & 687 & 687 & 963 & 962 \\
\hline R-squared & 0.276 & 0.291 & 0.214 & 0.223 \\
\hline
\end{tabular}

Subjects failing the comprehension questions are excluded in columns 1 and 2, and included in columns 3 and 4 .

Robust standard errors in parentheses.

${ }^{* *} p<0.01,{ }^{*} p<0.05$.

dilemma) would be expected to increase giving, whereas comprehension failure in the No Dilemma condition (i.e., not understanding that there is no dilemma) would be expected to decrease giving. Doing so, we continue to find a significant four-way interaction between time pressure, naivety, trust and being in the Social Dilemma condition (Table $3 \mathrm{Col} 3, p=0.019$; with demographic controls: Table $3 \mathrm{Col} 4, p=0.023)$. Thus, the difference we showed above in the effect of time pressure between the Social Dilemma and No Dilemma conditions is not the result of excluding non-comprehenders.

Finally, we note that there is no evidence of a potentially confounding relationship between trust and naivety: trust levels do not differ significantly between naïve and experienced subjects $\left[t\right.$-test, $\left.t_{(960)}=-0.05, p=0.96\right]$.

\section{DISCUSSION}

Here we have examined the effect of aligning individual and group incentives on intuitive (time pressured) and reflective (time delayed) public goods provisioning. We extended earlier results (Rand et al., 2012, 2014b) by showing that time pressure increased cooperation in a social dilemma only among participants who were both naïve and trusting. We then showed that promoting intuition had no effect on cooperation when the conflict between individual and collective incentives was removed (by making contribution individually payoff maximizing). These results confirm our predictions generated by the SHH (Rand et al., 2014b), and provide evidence that deliberation undermines cooperation in social dilemmas specifically by leading participants toward self-interest.

An important limitation of the current study is that our assessment of the moderating roles of trust and prior experience takes an individual differences approach, rather than an experimental approach. Both of these measures are self-reports, and thus may be prone to inaccuracy. Moreover, the trust measure used here (and in Rand et al., 2012) is a generalized trust measure, which may be less effective at tapping into trust in interpersonal interactions than other more targeted measures (Simpson, 2007). One might also worry that choosing to cooperate in the PGG makes people report a high level of trust in the subsequent demographics questionnaire. However, our data suggest that this is not so: if this was the case, we should expect a main effect of trust on cooperation and not the interaction that we observe. The three-way interaction we find between trust, experience, and condition (Prediction 1) provides some evidence that time pressure makes people more cooperative when they are trusting and inexperienced, rather than trust making people more cooperative overall. Further, subjects learned the outcome of the group decision after making trust judgments. Therefore, it is not possible that the behavior of the group affected trust judgments. Nonetheless, future work should examine the effect of directly manipulating trust and experience on cooperation under time pressure/delay. 
Another important limitation involves our study's sample size. Although we recruited a large number of subjects $(N=963)$, our four-way interaction structure (payoff structure $\times$ time constraint $x$ trust of daily life interaction partners $\times$ naivety) and high rate of comprehension failure meant that we wound up with relatively few subjects in each bin. In particular, we had only 34 subjects who were naïve, had higher than median trust, and passed the comprehension checks. Thus, future studies are needed, using even larger sample sizes, to assess the robustness of our findings.

The SHH predicts that prior experience with economic games will reduce the effect of time pressure in the social dilemma (Rand et al., 2012, 2014b). The mechanism by which this occurs, however, remains somewhat unclear. There are two possibilities. One is that with sufficient experience, subjects develop new default responses tailored to one-shot anonymous games. Alternatively, it could be that experience with economic game experiments (and psychological experiments more generally) does not change subjects' default responses, but instead teaches them not to rely on those defaults; repeatedly exposing subjects to situations in which their defaults lead them astray may undermine their faith in the accuracy of their intuitions. The present study helps to differentiate between these possibilities in two different ways.

First, the No Dilemma condition lets us look for evidence of remodeled intuitions. If subjects developed new non-cooperative defaults for one-shot economic games (where it is typically payoff maximizing to not contribute), we might expect time pressure to reduce cooperation among experienced subjects in the No Dilemma condition: remodeled intuitions would favor noncontribution while deliberation would cause people to realize that contributing was payoff-maximizing in the variant. Yet we find no significant effect of time pressure among experienced subjects in the No Dilemma condition (coeff $=-0.34, p=0.737$ ). Thus, it seems our subjects have not developed new non-cooperative intuitions.

Second, we do find evidence that experienced subjects are more skeptical of their intuitive responses. As an exploratory measure, our post-experimental questionnaire included one item from the "Faith in intuition" scale (Epstein et al., 1996) which asks how much subjects agree with the statement "I trust my initial feelings about people" using a 5 point Likert scale from "Very untrue" to "Very true." This particular item was selected because Epstein et al. (1996) found it to be the item that loaded most heavily on their "faith in intuition" factor. We find that among those passing the comprehension checks, naïve subjects report significantly higher agreement (Mean 3.893, SE 0.085) compared to experienced subjects [Mean 3.700, SE 0.035; $t$-test $t_{(685)}=2.12$, $p=0.034]$. In particular, naïve subjects are significantly more likely to report maximum agreement ["Very true"; naïve $24.3 \%$, experienced 14.4\%; $\operatorname{chi} 2_{(1)}=6.41, p=0.011$ ]. Although the magnitudes of these differences are not so large, they provide preliminary evidence that experience with experiments undermines subjects' faith in their intuition, rather than remodeling the contents of those intuitions.

Based on the SHH, one might expect that in the No Dilemma condition, time pressure would decrease cooperation in low-trust subjects (because their intuitions should favor selfishness, while deliberation makes them realize that here it is advantageous to contribute). While we did not observe such an interaction, this is likely the result of having very few truly low-trust subjects in our sample (only $16.8 \%$ of subjects reported trust levels below the mid-point of the scale). Thus, we did not have sufficient power to detect such an effect. Examining this possibility is an important direction for future work, perhaps using cross-cultural studies in cultures with overall lower trust.

In addition to illuminating the cognitive underpinnings of cooperation, our findings may have important implications for policies aimed at increasing contributions to the public good. They suggest that in situations where people believe that it is individually costly for them to contribute, deliberation may undermine cooperation. However, when it is clear that contribution is good for the individual as well as for the group, cooperation is safe from negative effects of deliberation. Therefore, wherever organization structures are aimed at aligning individual and collective interests, such as reputation systems or profit sharing, this alignment should be made salient. Not only could this increase overall cooperation, but it could in particular facilitate cooperation in the contexts that rely on rational, deliberative decision-making.

\section{ACKNOWLEDGMENTS}

The authors gratefully acknowledge funding from the John Templeton Foundation, as well as helpful comments and feedback from Fiery Cushman, Alex Peysakhovich, and Jillian Jordan.

\section{REFERENCES}

Amir, O., Rand, D. G., and Gal, Y. K. (2012). Economic games on the internet: the effect of \$1 stakes. PLoS ONE 7:e31461. doi: 10.1371/journal.pone.0031461

Apicella, C. L., Marlowe, F. W., Fowler, J. H., and Christakis, N. A. (2012). Social networks and cooperation in hunter-gatherers. Nature 481, 497-501. doi: 10.1038/nature10736

Axelrod, R. (1984). The Evolution of Cooperation. New York, NY: Basic Books.

Bartlett, M. Y., and Desteno, D. (2006). Gratitude and prosocial behavior: helping when it costs you. Psychol. Sci. 17, 319-325. doi: 10.1111/j.14679280.2006.01705.x

Batson, C. D., and Moran, T. (1999). Empathy-induced altruism in a prisoner's dilemma. Eur. J. Soc. Psychol. 29, 909-924. doi: 10.1002/(SICI)1099-0992 (199911)29:7<909::AID-EJSP965>3.0.CO;2-L

Bowles, S., and Gintis, H. (2002). "Prosocial emotions," in The Economy as a Evolving Complex System 3, eds L. Blume and S. N. Durlauf (Oxford: Oxford University Press), 339-364.

Bowles, S., and Gintis, H. (2003). "Origins of human cooperation," in Genetic and Cultural Evolution of Cooperation, ed P. Hammerstein (Cambridge, MA: MIT Press), 429-443.

Boyd, R., Gintis, H., Bowles, S., and Richerson, P. J. (2003). The evolution of altruistic punishment. Proc. Natl. Acad. Sci. U.S.A. 100, 3531-3535. doi: 10.1073/pnas.0630443100

Brandts, J., Saijo, T., and Schram, A. (2004). How universal is behavior? A four country comparison of spite and cooperation in voluntary contribution mechanisms. Public Choice 119, 381-424. doi: 10.1023/B:PUCH.0000033329.53 $595.1 \mathrm{~b}$

Buhrmester, M. D., Kwang, T., and Gosling, S. D. (2011). Amazon's mechanical turk: a new source of inexpensive, yet high-quality, data? Perspect. Psychol. Sci. 6, 3-5. doi: 10.1177/1745691610393980

Chaiken, S., and Trope, Y. (1999). Dual-process Theories in Social Psychology. New York, NY: Guilford Press.

Chudek, M., and Henrich, J. (2011). Culture gene coevolution, norm-psychology and the emergence of human prosociality. Trends Cogn. Sci. 15, 218-226. doi: 10.1016/j.tics.2011.03.003 
Cornelissen, G., Dewitte, S., and Warlop, L. (2011). Are social value orientations expressed automatically? Decision making in the dictator game. Pers. Soc. Psychol. Bull. 37, 1080-1090. doi: 10.1177/0146167211405996

Crockett, M. J. (2009). The neurochemistry of fairness. Ann. N.Y. Acad. Sci. 1167, 76-86. doi: 10.1111/j.1749-6632.2009.04506.x

Cushman, F., and Macindoe, O. (2009). "The coevolution of punishment and prosociality among learning agents," in Proceedings of the 31st Annual Conference of the Cognitive Science Society (Amsterdam).

Dal Bó, P. (2005). Cooperation under the shadow of the future: experimental evidence from infinitely repeated games. Am. Econ. Rev. 95, 1591-1604. doi: $10.1257 / 000282805775014434$

Dal Bó, P., and Fréchette, G. R. (2011). The evolution of cooperation in infinitely repeated games: experimental evidence. Am. Econ. Rev. 101, 411-429. doi: 10.1257/aer.101.1.411

Engel, C., and Rand, D. G. (2014). What does "clean" really mean? The implicit framing of decontextualized experiments. Econ. Lett. 122, 386-389. doi: 10.1016/j.econlet.2013.12.020

Epstein, S., Pacini, R., Denes-Raj, V., and Heier, H. (1996). Individual differences in intuitive-experiential and analytical-rational thinking styles. J. Pers. Soc. Psychol. 71, 390-405. doi: 10.1037/0022-3514.71.2.390

Espín, A. M., Brañas-Garza, P., Herrmann, B., and Gamella, J. F. (2012). Patient and impatient punishers of free-riders. Proc. R. Soc. B Biol. Sci. 279, 4923-4928. doi: 10.1098/rspb.2012.2043

Evans, A. M., Dillon, K. D., and Rand, D. G. (2014). Reaction Times and Reflection in Social Dilemmas: Extreme Responses are Fast, But Not Intuitive. Available online at: http://ssrn.com/abstract $=2436750$

Fehr, E., and Fischbacher, U. (2003). The nature of human altruism. Nature 425, 785-791. doi: 10.1038/nature02043

Frederick, S. (2005). Cognitive reflection and decision making. J. Econ. Perspect. 19, 25-42. doi: 10.1257/089533005775196732

Fudenberg, D., Rand, D. G., and Dreber, A. (2012). Slow to anger and fast to forgive: cooperation in an uncertain world. Am. Econ. Rev. 102, 720-749. doi: 10.1257/aer.102.2.720

Goetz, J. L., Keltner, D., and Simon-Thomas, E. (2010). Compassion: an evolutionary analysis and empirical review. Psychol. Bull. 136, 351-374. doi: 10.1037/a0018807

Hardin, G. (1968). The tragedy of the commons. Science 162, 1243-1248. doi: 10.1126/science.162.3859.1243

Hauge, K. E., Brekke, K. A., Johansson, L.-O., Johansson-Stenman, O., and Svedsäter, H. (2009). "Are social preferences skin deep? Dictators under cognitive load," in University of Gothenburg Working Papers in Economics (Gothenburg: Institution for National Economics and Statistics, Business School at the University of Gothenburg).

Hauser, O. P., Rand, D. G., Peysakhovich, A., and Nowak, M. A. (2014). Cooperating with the future. Nature 511, 220-223. doi: 10.1038/nature 13530

Henrich, J., Boyd, R., Bowles, S., Camerer, C., Fehr, E., Gintis, H., et al. (2005). "Economic man" in cross-cultural perspective: behavioral experiments in 15 small-scale societies. Behav. Brain Sci. 28, 795-855. doi: 10.1017/S0140525X05000142

Henrich, J., Ensminger, J., McElreath, R., Barr, A., Barrett, C., Bolyanatz, A., et al. (2010). Markets, religion, community size, and the evolution of fairness and punishment. Science 327, 1480-1484. doi: 10.1126/science.11 82238

Herrmann, B., Thoni, C., and Gächter, S. (2008). Antisocial punishment across societies. Science 319, 1362-1367. doi: 10.1126/science.1153808

Horton, J. J., Rand, D. G., and Zeckhauser, R. J. (2011). The online laboratory: conducting experiments in a real labor market. Exp. Econ. 14, 399-425. doi: 10.1007/s10683-011-9273-9

Kahneman, D. (2003). A perspective on judgment and choice: mapping bounded rationality. Am. Psychol. 58, 697-720. doi: 10.1037/0003-066X.58 .9 .697

Kummerli, R., Burton-Chellew, M. N., Ross-Gillespie, A., and West, S. A. (2010). Resistance to extreme strategies, rather than prosocial preferences, can explain human cooperation in public goods games. Proc. Natl. Acad. Sci. U.S.A. 107, 10125-10130. doi: 10.1073/pnas. 1000829107

Levin, S. (2006). Learning to live in a global commons: socioeconomic challenges for a sustainable environment. Ecol. Res. 21, 328-333. doi: 10.1007/s11284-0060162-1
Milinski, M., Semmann, D., and Krambeck, H. J. (2002). Reputation helps solve the 'tragedy of the commons.' Nature 415, 424-426. doi: 10.1038/415424a

Miller, E. K., and Cohen, J. D. (2001). An integrative theory of prefrontal cortex function. Annu. Rev. Neurosci. 24, 167-202. doi: 10.1146/annurev.neuro. 24.1.167

Nielsen, U. H., Tyran, J. R., and Wengström, E. (2014). Second thoughts on free riding. Econ. Lett. 122, 136-139. doi: 10.1016/j.econlet.2013.11.021

Nowak, M. A., and Sigmund, K. (2005). Evolution of indirect reciprocity. Nature 437, 1291-1298. doi: 10.1038/nature04131

Ostrom, E. (1990). Governing the Commons: The Evolution of Institutions for Collective Action. Cambridge: Cambridge University Press.

Paolacci, G., Chandler, J., and Ipeirotis, P. G. (2010). Running experiments on amazon mechanical turk. Judgm. Decis. Mak. 5, 411-419.

Peysakhovich, A., Nowak, M. A., and Rand, D. G. (2014). Humans Display a 'Cooperative Phenotype' that is Domain General and Temporally Stable. Available online at: http://ssrn.com/abstract $=2426472$

Peysakhovich, A., and Rand, D. G. (2013). Habits of Virtue: Creating Norms of Cooperation and Defection in the Laboratory. Available online at: http://ssrn. com/abstract $=2294242$

Piff, P., Stancato, D., Cote, S., Mendoza-Denton, R., and Keltner, D. (2012). Higher social class predicts increased unethical behavior. Proc. Natl. Acad. Sci. U.S.A. 109, 4086-4091. doi: 10.1073/pnas.1118373109

Piovesan, M., and Wengström, E. (2009). Fast or fair? A study of response times. Econ. Lett. 105, 193-196. doi: 10.1016/j.econlet.2009.07.017

Rand, D. G. (2012). The promise of Mechanical Turk: how online labor markets can help theorists run behavioral experiments. J. Theor. Biol. 299, 172-179. doi: 10.1016/j.jtbi.2011.03.004

Rand, D. G., Dreber, A., Ellingsen, T., Fudenberg, D., and Nowak, M. A. (2009). Positive interactions promote public cooperation. Science 325, 1272-1275. doi: $10.1126 /$ science. 1177418

Rand, D. G., Greene, J. D., and Nowak, M. A. (2012). Spontaneous giving and calculated greed. Nature 489, 427-430. doi: 10.1038/nature11467

Rand, D. G., Greene, J. D., and Nowak, M. A. (2013). Rand et al. reply. Nature 498, E2-E3. doi: 10.1038/nature12195

Rand, D. G., and Nowak, M. A. (2013). Human cooperation. Trends Cogn. Sci. 17, 413-425. doi: 10.1016/j.tics.2013.06.003

Rand, D. G., Newman, G. E., and Wurzbacher, O. (2014a). Social context and the dynamics of cooperative choice. J. Behav. Decis. Making. doi: 10.1002/bdm.1837. (in press).

Rand, D. G., Peysakhovich, A., Kraft-Todd, G. T., Newman, G. E., Wurzbacher, O., Nowak, M. A., et al. (2014b). Social heuristics shape intuitive cooperation. Nat. Commun. 5:3677. doi: 10.1038/ncomms4677

Rubinstein, A. (2007). Instinctive and cognitive reasoning: a study of response times. Econ. J. 117, 1243-1259. doi: 10.1111/j.1468-0297.2007.02081.x

Ruff, C. C., Ugazio, G., and Fehr, E. (2013). Changing social norm compliance with noninvasive brain stimulation. Science 342, 482-484. doi: 10.1126/science. 1241399

Saijo, T., and Nakamura, H. (1995). The "spite" dilemma in voluntary contribution mechanism experiments. J. Conflict Resol. 39, 535-560. doi: $10.1177 / 0022002795039003007$

Schulz, J. F., Fischbacher, U., Thöni, C., and Utikal, V. (2014). Affect and fairness: dictator games under cognitive load. J. Econ. Psychol. 41, 77-87. doi: 10.1016/j.joep.2012.08.007

Sigmund, K. (2010). The calculus of Selfishness. Princeton: Princeton University Press.

Simpson, J. A. (2007). "Foundations of interpersonal trust," in Social Psychology: Handbook of Basic Principles, 2nd Edn, eds A. W. Kruglanski and E. T. Higgins (New York, NY: Guilford Press), 587-607.

Sloman, S. A. (1996). The empirical case for two systems of reasoning. Psychol. Bull. 119:3. doi: 10.1037/0033-2909.119.1.3

Stanovich, K. E., and West, R. F. (1998). Individual differences in rational thought. J. Exp. Psychol. Gen. 127, 161-188. doi: 10.1037/0096-3445.127.2.161

Tinghög, G., Andersson, D., Bonn, C., Böttiger, H., Josephson, C., Lundgren, G., et al. (2013). Intuition and cooperation reconsidered. Nature 497, E1-E2. doi: 10.1038 /nature12194

Verkoeijen, P. P. J. L., and Bouwmeester, S. (2014). Does intuition cause cooperation? PLoS ONE 9:e96654. doi: 10.1371/journal.pone.0096654

Zaki, J., and Mitchell, J. P. (2011). Equitable decision making is associated with neural markers of intrinsic value. Proc. Natl. Acad. Sci. U.S.A. 108, 19761-19766. doi: $10.1073 /$ pnas. 1112324108 
Zaki, J., and Mitchell, J. P. (2013). Intuitive prosociality. Curr. Dir. Psychol. Sci. 22, 466-470. doi: 10.1177/0963721413492764

Conflict of Interest Statement: The authors declare that the research was conducted in the absence of any commercial or financial relationships that could be construed as a potential conflict of interest.

Received: 01 July 2014; paper pending published: 26 July 2014; accepted: 15 August 2014; published online: 03 September 2014.
Citation: Rand DG and Kraft-Todd GT (2014) Reflection does not undermine selfinterested prosociality. Front. Behav. Neurosci. 8:300. doi: 10.3389/fnbeh.2014.00300 This article was submitted to the journal Frontiers in Behavioral Neuroscience.

Copyright () 2014 Rand and Kraft-Todd. This is an open-access article distributed under the terms of the Creative Commons Attribution License (CC BY). The use, distribution or reproduction in other forums is permitted, provided the original author(s) or licensor are credited and that the original publication in this journal is cited, in accordance with accepted academic practice. No use, distribution or reproduction is permitted which does not comply with these terms. 